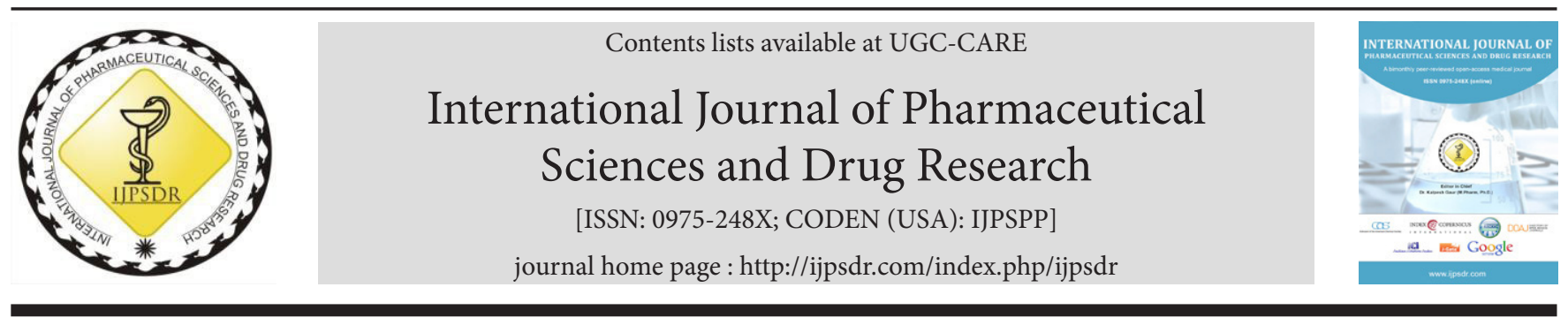

Research Article

\title{
Biosynthesis, Characterization, Bactericidal, and Toxic Effect of Silver Nanoparticles using Klebsiella pneumoniae Strain STC1
}

\author{
S. Febina Bernice Sharon ${ }^{1 *}$, Anitha Ganesan ${ }^{2}$ \\ ${ }^{1}$ Department of Food Science and Nutrition, Sarah Tucker College, Tirunelveli, Tamil Nadu, India \\ ${ }^{2}$ Department of Nanoscience, Sarah Tucker College, Tirunelveli, Tamil Nadu, India
}

\begin{tabular}{l} 
A R T I C L E I N F O \\
\hline Article history: \\
Received: 25 May, 2020 \\
Revised: 21 July, 2020 \\
Accepted: 12 August, 2020 \\
Published: 30 September, 2020 \\
Keywords: \\
Antibacterial, \\
Artemia cysts, \\
Biological synthesis, \\
Methicillin-resistant \\
Staphylococcus aureus, \\
Silver nanoparticles, \\
Toxicity. \\
D0I: \\
10.25004/IJPSDR.2020.120514
\end{tabular}

\begin{abstract}
A B S T R A C T
Nanotechnology dealt with nanoparticles having a size of 1 to $100 \mathrm{~nm}$ used significantly in pharmaceutical science and many other fields. The use of microorganisms in the synthesis of nanoparticles emerged as an ecofriendly method. Klebsiella pneumoniae strain STC1 was isolated from cow's milk and identified by 16S rRNA sequencing. The biosynthesis was done using the fixed ratio of aqueous solution of the bacterial supernatant and $\mathrm{AgNO}_{3}$, and the color change was observed, which proved the formation of silver nanoparticles. The nanoparticles were characterized by ultra violet (UV)-visible spectrophotometer, Fourier transform infrared spectroscopy (FTIR), X-ray powder diffraction (XRD), and scanning electron microscope (SEM). The nanoparticles were found to have sizes ranging from 15 to $70 \mathrm{~nm}$. The antibacterial activity of silver nanoparticles was studied against methicillin-resistant Staphylococcus aureus, Clostridium perfringens, Pseudomonas sp., and Proteus sp. The minimum inhibitory concentration of silver nanoparticles was found to be $50 \mu \mathrm{g} / \mathrm{mL}$, against methicillin-resistant $S$. aureus. The synergistic effect of the silver nanoparticles with commercial antibiotics erythromycin and tetracycline was found to be more evident. The time-kill assay and the cytoplasm diffusion assay showed the effectiveness of synthesized silver nanoparticles in the study. The synthesized silver nanoparticles had a great antibacterial potential against methicillin-resistant $S$. aureus. The toxic effect of silver nanoparticles revealed that as the concentration of the silver nanoparticles increased, the effect of toxicity increased, and the hatching percentage of Artemia cysts decreased. This present study's innovation is that the biosynthesis of nanoparticles is simple, cost-effective, providing good bactericidal and cytotoxic activity. It can represent a future for more therapeutic and pharmacological applications.
\end{abstract}

\section{INTRODUCTION}

Nanotechnology was the art and science of manipulation of matter on an atomic and molecular scale, which resulted in 100,000 times smaller than a strand of human hair to make useful materials and devices. ${ }^{[1]}$ Nanoparticles revealed new or improved properties, and these properties were due to variation in specific characteristics, such as, size, distribution, and morphology of the particles. Biosynthesis of metallic silver nanoparticles was attracting attention due to the positive environmental impact of using microorganisms in the production of nanoparticles. ${ }^{[2]}$

Human beings were often infected by microorganisms and the on-going emergence of multi drug-resistant bacteria, and the infections caused by them was on the rise. So there is a vital need to modify the existing drugs or find novel strategies to overcome this crisis. In the recent past, silver nanoparticles had gained the attention of researchers worldwide due to their potential antimicrobial activities. ${ }^{[2,3]}$ The antibacterial effect was influenced by blocking respiratory enzyme pathways, interacting with the sulfur-containing proteins, and modification of microbial DNA. In the present study, the synthesized nanoparticles were characterized by UV, FTIR, XRD, and SEM. The nanoparticles were further characterized to evaluate their antibacterial activity, minimum inhibitory and bactericidal concentration, cytoplasm leakage analysis, and toxicity analysis using Artemia nauplii.

\footnotetext{
${ }^{*}$ Corresponding Author: Dr. S. Febina Bernice Sharon

Address: Department of Food Science and Nutrition, Sarah Tucker College, Tirunelveli, Tamil Nadu, India

Email $\bowtie$ : febina.623@gmail.com

Relevant conflicts of interest/financial disclosures: The authors declare that the research was conducted in the absence of any commercial or financial relationships that could be construed as a potential conflict of interest.

Copyright (C) 2020 S. Febina Bernice Sharon et al. This is an open access article distributed under the terms of the Creative Commons AttributionNonCommercial-ShareAlike 4.0 International License which allows others to remix, tweak, and build upon the work non-commercially, as long as the author is credited and the new creations are licensed under the identical terms.
} 


\section{Material AND Methods}

\section{Isolation and Characterization of Bacteria}

The milk sample was taken in a sterile swab and incubated in nutrient broth for 24 hours at $37^{\circ} \mathrm{C}$. The sample was streaked on the surface of nutrient agar and MacConkey agar (Himedia) plates and incubated for 24 hours. The isolated bacterial strain was identified by morphological and biochemical tests as per Bergey's manual (1964) ${ }^{[4]}$ and confirmed by $16 \mathrm{~S}$ rRNA gene sequencing.

The bacterial colonies were suspended in $0.5 \mathrm{~mL}$ of sterile saline and centrifuged at $10,000 \mathrm{rpm}$ for 10 minutes. The pellet was suspended in $0.5 \mathrm{~mL}$ of InstaGene Matrix (Bio-Rad, USA) and incubated at $56^{\circ} \mathrm{C}$ for 30 minutes and then heated for $100^{\circ} \mathrm{C}$ for 10 minutes. ${ }^{[5]}$ The supernatant was used for polymerase chain reaction (PCR). The unincorporated primers and dNTPs were removed by utilizing a Montage PCR clean-up kit.

The PCR product was sequenced using the forward (5'AGAGTTTGATCCTGGCTCAG3') and reverse (5'AAGGAGGTGATCCAGCCGCA3') primers. The purified PCR product was extracted from the gel and sequenced by cycle sequencing kits with AmpliTaq ${ }^{\circledR}$ DNA polymerase using ABIPRISM ${ }^{\circledR}$ BigDye $^{\mathrm{TM}}$ Terminator cycle sequencing 3730XL sequencer. Nucleotide sequences were compared with other 16S rRNA sequences, maintained by the GenBank database, using the National Center for Biotechnology Information (NCBI)-BLAST program. The sequences were aligned by CLUSTAL $\mathrm{W}$, and the phylogenetic tree was constructed using MEGA X with the neighbor-joining method. All these analyses were performed on a bootstrapped dataset containing 1,000 replicates.

\section{Biosynthesis of Silver Nanoparticles}

The supernatant of K. pneumoniae strain STC1 was added with $10 \mathrm{mM}$ concentration of silver nitrate (Fisher Scientific) solution in the ratio 2:1, and another reaction mixture was prepared without silver nitrate and used as control. The prepared solutions were incubated at $30^{\circ} \mathrm{C}$ for 24 hours in the dark. After incubation, the silver nanoparticles were purified by centrifugation at $5,200 \mathrm{rpm}$ for 30 minutes thrice, and the pellet was collected for further characterization. ${ }^{[6]}$

\section{Characterization of Silver Nanoparticles}

The supernatant of $K$. pneumoniae strain STC1 was added to a $10 \mathrm{mM}$ concentration of silver nitrate. One drop of this mix was placed on a microscopic slide and covered with a coverslip. ${ }^{[2]}$ Crystal formation was examined at 6 and 24 hours by a light microscope. UV-visible spectrophotometer analysis was carried out with Shimadzu UV spectrophotometer (model UV-1800) in a wavelength range of 200 to $800 \mathrm{~nm} \cdot{ }^{[7]}$ FTIR spectroscopy analysis (Perkin Elmer Spectrum-one, USA) of synthesized nanoparticles was performed to identify functional groups in the silver nanoparticles. To perform FTIR, the sample was mixed with $\mathrm{KBr}$ powder and pelletized. After drying the spectrum, data were recorded using Perkin Elmer with a wavelength range between 4,000 and $400 \mathrm{~cm}^{-1}$. [8]

The dried silver nanoparticles were analyzed by XRD, using X-ray diffractometer D8 Advance ECO, Bruker. The dried powder of silver nanoparticles was placed on the glass slide, and the analysis was carried out on an instrument operating at $40 \mathrm{Kv}, 40 \mathrm{~mA}$ at a $2 \theta$ angle. The pattern was recorded by $\mathrm{Cu} \alpha$ radiation with $\lambda$ of $1.5406 \mathrm{~nm}$ and nickel monochromator. ${ }^{[9]}$ The scanning was performed from 20 to $80^{\circ}$ in the region of $2 \theta$. The size of the silver nanoparticles was calculated using the Scherrer equation. The surface morphology of the silver nanoparticles was investigated by scanning electron microscopy (JOEL-JSM 6390). A drop of silver nanoparticles was placed over a carbon-coated grid and dried. The instrument functioned at $20 \mathrm{kV}$.

\section{Antibacterial Activity of Silver Nanoparticles against Bacteria}

The synthesized silver nanoparticles were checked for their antibacterial potential against methicillin-resistant S. aureus, C. perfringens, Pseudomonas sp., and Proteus sp. The bacterial cultures were obtained from the Department of Veterinary Microbiology, Veterinary College and Research Institute, Ramayanpatti, Tirunelveli, Tamil Nadu, India. The commercial antibiotics, erythromycin, and tetracycline were used as positive controls, and their effectiveness was compared with silver nanoparticles. The antibacterial activity of silver nanoparticles was evaluated by the Kirby Bauer agar well method and disc diffusion method. ${ }^{[10]}$ For the agar well diffusion method, $125 \mu \mathrm{L}$ of the silver nanoparticles were loaded into the well.

For the disc diffusion method, sterile discs were impregnated with silver nanoparticles $(5 \mathrm{mg} / \mathrm{mL})$ and dried. The bacterial culture plates were incubated at $37^{\circ} \mathrm{C}$ for 18 to 24 hours, and the diameter of the circular inhibition zones was measured. The experiment was carried out in triplicates, and the results were expressed in mean \pm standard deviation. The one-way analysis of variance (ANOVA) was used to find the significance level. The bacterium with the highest zone of inhibition was selected for further studies.

\section{Tolerance Level}

The minimum inhibitory concentration (MIC) and minimum bactericidal concentration (MBC) values were determined by microdilution and plating method in nutrient medium. The tolerance levels against the silver nanoparticles were determined for the bacterial strain using the following formula. ${ }^{[1]}$

$$
\text { Tolerance }=\mathrm{MBC} / \mathrm{MIC}
$$

The bacteriostatic and bactericidal capacity of the analysed silver nanoparticles was detected by the tolerance level. If the ratio was $\geq 16$, then the agent had 
a bacteriostatic effect, whereas ratio $\leq 4$ reflected the examined material's bactericidal ability. ${ }^{[12]}$

\section{Time-Kill Assay}

The silver nanoparticles' time-kill assay was done by determining bacterial cell death rate with respect to time against methicillin-resistant $S$. aureus. ${ }^{[13]}$ The bacterial suspension was diluted to 1 in $100 \mathrm{~mL}$ nutrient broth, and it was inoculated into a $50 \mathrm{~mL}$ of Muller Hinton broth combined with $50 \mu \mathrm{g} / \mathrm{mL}$ of silver nanoparticles. ${ }^{[14]}$ The flasks were incubated at room temperature at $100 \mathrm{rpm}^{\left[{ }^{15]}\right.}$ The bacterial growth after treatment of silver nanoparticles at $0,5,15,30$ minutes, 1,3 , and 6 hours were measured by spectrophotometer at $600 \mathrm{~nm}$. The difference in optical density between control and test were noted after the period of incubation. The reduction in optical density (OD) values indicated the inhibition activity of silver nanoparticles. A loopful of culture was streaked on Muller Hinton agar plates and incubated at $37^{\circ} \mathrm{C}$ for 24 hours to confirm the results. Muller Hinton broth inoculated with methicillin-resistant $S$. aureus without silver nanoparticles was considered as control. ${ }^{[16]}$

\section{Synergistic Activity of Silver Nanoparticles with Commercial Antibiotics}

The synergistic antibacterial effects of silver nanoparticles $(50 \mu \mathrm{g} / \mathrm{mL})$ with tetracycline or erythromycin $(50 \mu \mathrm{g} / \mathrm{mL})$ were tested against methicillin-resistant $S$. aureus using the disk diffusion method. ${ }^{[17]}$ After 24 hours of incubation, the diameter of the circular inhibition zones was measured. ${ }^{[7]}$ The experiment was carried out in triplicates, and the results were expressed in mean \pm standard deviation.

\section{Cytoplasm Leakage Analysis}

For preliminary identification, $1 \mathrm{~mL}$ of the supernatant (bacteria treated with $50 \mu \mathrm{g} / \mathrm{mL}$ silver nanoparticles) was taken, and a few drops of $2 \%$ ninhydrin were added to the test tube. Distilled water acted as the control. The test tubes were kept in a water bath for 5 minutes. Optical density was measured at $260 \mathrm{~nm}$ after the development of violet color. ${ }^{[18]}$ Protein leakage analysis was performed using the Bradford assay. Bacterial cells of methicillin-resistant $S$. aureus were treated with $50 \mu \mathrm{g} / \mathrm{mL}$ silver nanoparticle solutions for 1 and 3 hours. The supernatant was collected after centrifugation at $5,000 \mathrm{rpm}$ for 20 minutes. For each sample, $200 \mu \mathrm{L}$ of the supernatant was mixed with $800 \mu \mathrm{L}$ of the Bradford reagent. Optical density was measured at $595 \mathrm{~nm}$ after 10 minutes of incubation in the dark. ${ }^{[18]}$

\section{Toxicity Effect of Silver Nanoparticles}

Brine Shrimp lethality bioassay was a modern assay of bioactive compounds that showed cytotoxicity and other pharmacological activities. It was a rapid, inexpensive, in-house, and general bioassay developed to screen and monitor physiologically active products. ${ }^{[19]}$ Artemia cysts were collected from Aquatic Remedies, Chennai, in the form of a capsule.

\section{Mortality Rate of Artemia Nauplii}

The acute toxicity was determined by measuring the adverse effect of silver nanoparticles on the brine shrimp Artemia nauplii survival and mortality. The study commenced with $<24$ hours old nauplii and continued and exposed it for 24 and 48 hours. ${ }^{[20]}$ The experiment was performed in a beaker containing saline water along with control (without silver nanoparticles). About 50 nauplii were transferred with the addition of the desired concentration of silver nanoparticles, such as, 25, 50, and $75 \mu \mathrm{g}$, respectively. The percentages of mortality were calculated after 24 and 48 hours for silver nanoparticles and compared with the control. The results were tabulated.

Percentage mortality was calculated by following the formulae $e^{[21]}$

$$
\% \text { mortality }=\frac{\text { Number of dead Artemia nauplii }}{\text { Initial number of live Artemia nauplii }} \times 100
$$

\section{Hatching Percentage of Artemia Cyst}

The brine shrimp Artemia cysts were collected and processed and were used for testing the percentage of hatching. The experiments were performed in beakers. About 50 Artemia cysts were transferred with the addition of the desired concentration of silver nanoparticles, such as, 25,50 , and $75 \mu \mathrm{g}$. The experimental setup was allowed to remain for 24 hours in the shaker for aeration. The experimental set up was exposed to light to provide a favorable environment for the cyst to hatch out. The hatched cysts were counted after the incubation period of 24 hours. The percentages of hatching for various test concentrations of silver nanoparticles were determined.

The percentages of hatching for various test concentration of silver nanoparticle were calculated by the following formula:

$$
\mathrm{H} \%=\frac{\mathrm{N}}{\mathrm{C}+\mathrm{N}} \times 100
$$

Where $\mathrm{H}$ is the hatching percentage, $\mathrm{N}$ is the number of hatched cysts, including the umbrella stage, and $\mathrm{C}$ is the decapsulated full cysts. ${ }^{[22]}$ The results were tabulated.

\section{RESULTS AND Discussion}

\section{Isolation and Characterization of Bacteria}

Nanotechnology deals with nanoparticles with a size of 1 to $100 \mathrm{~nm}$ used significantly concerning medical chemistry and other known fields. Nanoparticles were used due to their small size, physical properties, orientation, and these particles could be synthesized by various physical, chemical, and biological approaches. The use of microorganisms in the synthesis of silver nanoparticles emerged as an eco-friendly and exhilarating approach. 
Pink color lactose fermenting colonies were observed on the MacConkey agar plates, whereas white color colonies were observed on nutrient agar plates. When the white colonies were streaked on the MacConkey agar plates, the colonies were large, shiny, and dark pink. All the isolated colonies were similar in their appearance. Therefore, a single colony was randomly selected, streaked on MacConkey agar plate, and used for further studies. The isolated bacterium was shown in Fig. 1.

The bacterium was found to be gram-negative, nonmotile, and rod-shaped. MacConkey agar was selective for gram-negative organisms and helped differentiate lactose fermenting gram-negative rods from non-lactose fermenting gram-negative rods. The bacteria was confirmed by biochemical tests, such as, indole negative, methyl red (MR) negative, Voges-Proskauer (VP) positive, citrate positive, oxidase negative, catalase positive, and nitrate reduction positive. The bacterium was found to be Klebsiella sp. by observing the colony morphology, lactose fermentation, and microscopic appearance.

The 16S rRNA gene sequence analysis was carried out to elucidate the taxonomic position and relationships among closely related species. The BLAST search of the $16 \mathrm{~S}$ rRNA sequences (1446 base pairs) of the bacterium showed 99.93\% similarity with $K$. pneumoniae strain TZT-1859 (MH922846.1) and K. pneumoniae sub sp. ozaenae strain OLM4 (MH542253.1). Based on the molecular taxonomy and phylogeny, it was identified as K. pneumoniae and designated as K. pneumoniae STC1. The nucleotide sequence of the 16S rRNA gene partial sequence was deposited in NCBI under the accession number (MK644104.1).

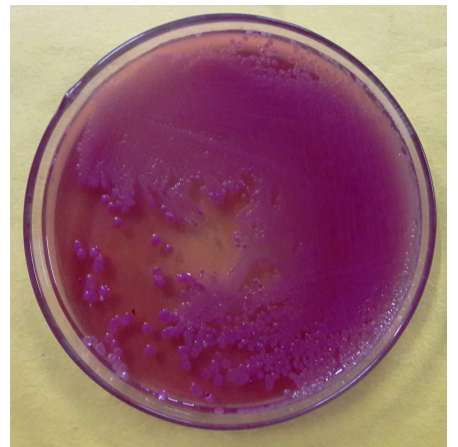

Fig. 1: Lactose fermenting bacterial colonies

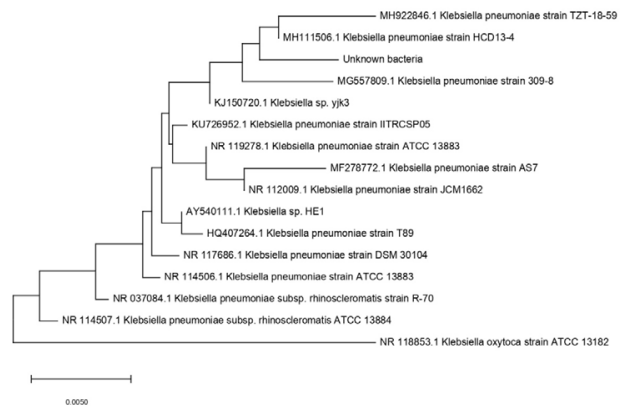

Fig. 2: Relationships between K. pneumoniae STC1 and other members of $K$. pneumoniae on rooted phylogenetic tree
A neighbor-joining tree based on the 16S rRNA sequence of $K$. pneumoniae STC1 showed that the isolate occupied a distinct phylogenetic position within the representatives of the Klebsiella family (Fig. 2). The numbers at the phylogenetic tree nodes indicated the levels of bootstrap support based on the analysis of 1,000 resampled data sets. The scale bar indicated 0.005 substitutions per nucleotide position.

\section{Biosynthesis and Characterization of Silver Nanoparticles}

The biosynthesis of silver nanoparticles was investigated by the visual observation of the color change of the sample in the presence of $10 \mathrm{mM}$ of silver nitrate. A color change from pale yellow to brown occurred within 24 hours. A visual change of color from yellow to brown might be due to the excitation of surface plasmon resonance in silver nanoparticles. ${ }^{[3]}$ This change in color was confirmed by other studies. ${ }^{[2,3,6,23]}$ The surface plasmon vibrations were due to the dipole oscillation arising when an electromagnetic field in the visible range was coupled to the collective oscillations of conduction electrons. ${ }^{[24]}$ The light microscopic images showed that silver nanoparticles' aggregates were precipitated outside the bacterial cells indicating an extracellular production of silver nanoparticles (Fig. 3).

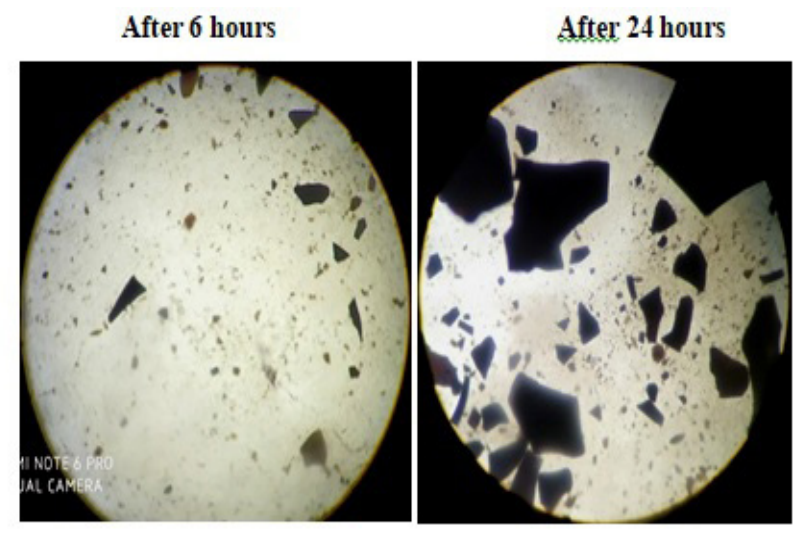

Fig. 3: Precipitation of silver nanoparticles aggregates under light microscope

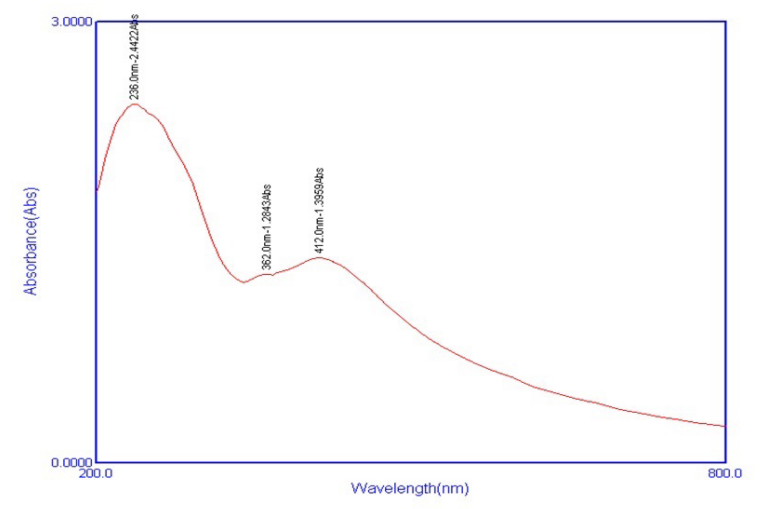

Fig. 4: Absorption spectrum of silver nanoparticles synthesized by K. pneumoniae STC1 culture supernatant 
A strong peak specific of silver nanoparticles was observed at $412 \mathrm{~nm}$ in a UV-visible spectrophotometer (Fig. 4). A characteristic surface plasmon absorption peak at $412 \mathrm{~nm}$ was observed at 24 hours. Similar to our findings, other researchers have also reported silver nanoparticles' formation by exhibiting the typical surface plasmon absorption maxima at nearly $412 \mathrm{~nm}$ from the UV-visible spectrum. ${ }^{[3,25]}$ The characterization of the silver nanoparticles was also investigated by analyzing FTIR spectra. The spectral analysis of the experimental sample was shown in Fig. 5. The bands observed between 1,000 to $1,600 \mathrm{~cm}^{-1}$ might be due to $\mathrm{C}=\mathrm{O}, \mathrm{C}-\mathrm{N}$, and $\mathrm{O}-\mathrm{H}$ functional groups' stretching vibrations, respectively. ${ }^{[3]}$ The absorbance band analysis in bioreduction was absorbed in the following regions, viz., 1,638.34, 2,923.74, and 3,422.10 $\mathrm{cm}^{-1}$.

XRD examination was an important technique for the characterization of crystal structure, determination of phase composition, detection of the presence of impurities, and detection of the crystalline size of powdered nanoparticles. The arrangement of atoms in a particular way created a unique pattern of planes and facets that characterize the crystal structure of a material. ${ }^{[2]}$ XRD displayed peaks of silver nanoparticles, which proved the precipitation of silver nanoparticles. The strong peaks resulted from XRD (Fig. 6) was located at $2 \theta$ values of $32.5,38.1,46.1,64.5$, and $77.5^{\circ}$. These values were matched well with the cubic crystal

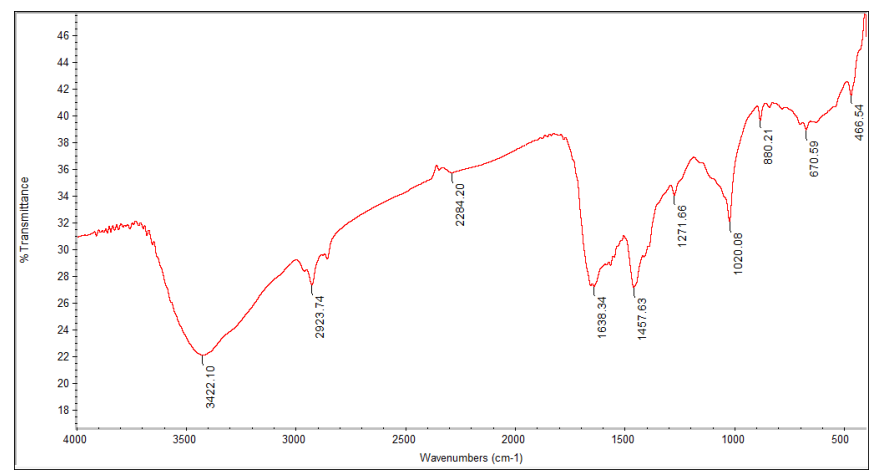

Fig. 5: FTIR spectrum of silver nanoparticles synthesized by K. pneumoniae STC1 culture supernatant

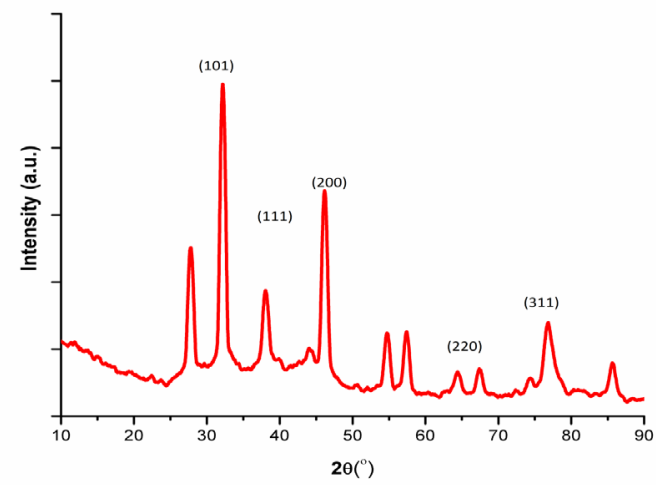

Fig. 6: XRD of silver nanoparticles lattice planes (101), (111), (200), (220), and (311), respectively, of silver metal, using the Joint Committee on Powder Diffraction Standards (JCPDS). The size of the silver nanoparticles ranged from 15 to $70 \mathrm{~nm}$. SEM micrograph showed that the silver nanoparticles were aggregated (Fig. 7). They were quasi-spherical in shape. The shape of the nanoparticle was quasispherical. According to Al-Thawadi et al., the aggregated nanoparticles have a role in microbial toxicity. ${ }^{[2]}$

\section{Antibacterial Activity of Silver Nanoparticles against Bacteria}

In the agar well diffusion method, Pseudomonas sp. had a maximum zone of inhibition. Culture filtrate inhibited C. perfringens better than other bacteria. The silver nanoparticles were able to inhibit all the pathogens. When comparing the antibacterial activity of the silver nanoparticles with the commercial antibiotics, the inhibitory level was not satisfactory. The silver nanoparticles were deposited at the bottom of the well, and hence, they were not able to penetrate within the agar medium and inhibit the bacterial pathogens.

In the disc diffusion method, Pseudomonas sp. had a maximum zone of inhibition for erythromycin and methicillin-resistant $S$. aureus for tetracycline. The silver nitrate solution and culture filtrate had minimum antibacterial activity. Culture filtrate inhibited C. perfringens better than the other three bacteria. The silver nanoparticles were able to inhibit methicillinresistant S. aureus, Proteus sp., C. perfringens, and Pseudomonas sp. (Fig. 8). The silver nanoparticles inhibited gram-positive bacteria better than gramnegative bacteria. When comparing the antibacterial activity of the silver nanoparticles with the commercial antibiotics, the silver nanoparticles inhibited methicillinresistant $S$. aureus better than and erythromycin. It also inhibited $C$. perfringens better than and erythromycin. A one-way ANOVA comparing the antibacterial activity of silver nanoparticles revealed that the differences in

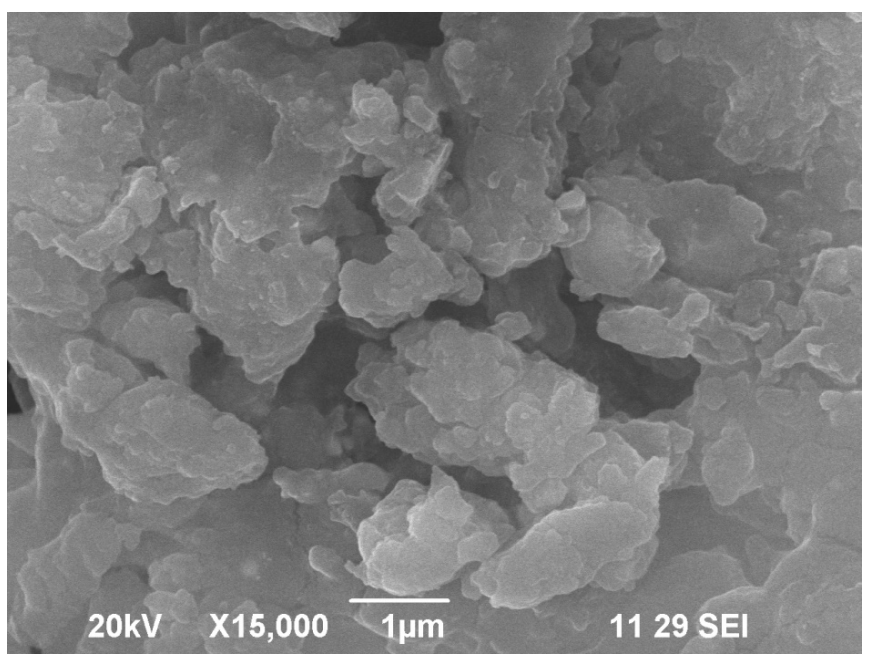

Fig. 7: SEM micrograph of silver nanoparticles 
S. Febina Bernice Sharon et al.

Table 1: ANOVA for antibacterial activity of silver nanoparticles by disc diffusion method

\begin{tabular}{llll}
\hline Name of bacterial pathogen & Fvalue & p value & Fcritical \\
\hline S. aureus & 20.44792 & 8.37146 & 3.47805 \\
Proteus sp. & 84.56522 & 1.14317 & 3.47805 \\
C. perfringens & 33.58824 & 9.02 & 3.47805 \\
Pseudomonas sp. & 70.4 & 2.76 & 3.47805 \\
\hline
\end{tabular}
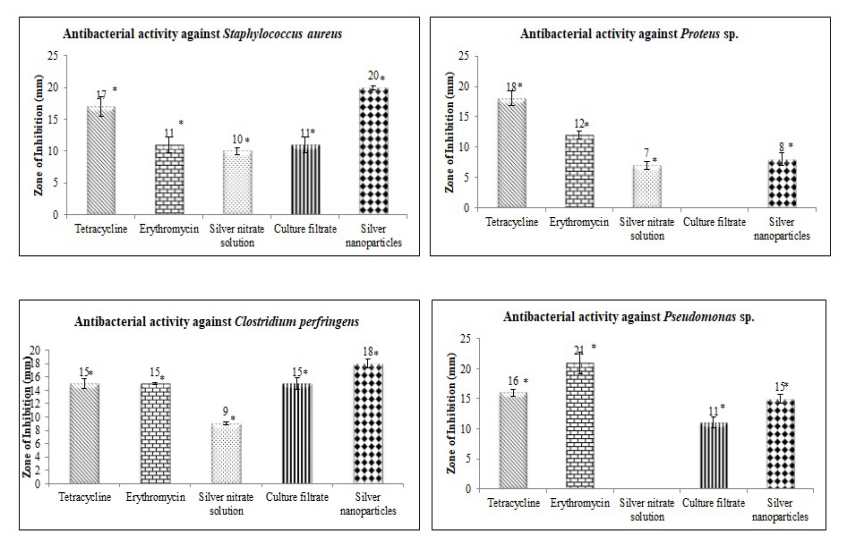

Fig. 8: Antibacterial activity of silver nanoparticles and commercial antibiotics against bacteria

antibacterial activity were statistically significant at $\mathrm{p}<0.05$ (Table 1).

The silver nanoparticles inhibited methicillin-resistant $S$. aureus better than other bacterial pathogens. Therefore, it was selected for further study. When the combination of antibiotics and nanoparticles worked effectively, it showed a synergistic effect against methicillin-resistant $S$. aureus.

The minimum inhibitory concentration of the silver nanoparticles was $50 \mu \mathrm{g} / \mathrm{mL}$, and the minimum bactericidal concentration was $75 \mu \mathrm{g} / \mathrm{mL}$. Furthermore, the $\mathrm{MBC} / \mathrm{MIC}$ ratio might reflect the susceptibility, tolerance, or resistance of $S$. aureus to the silver nanoparticles. The tolerance level for silver nanoparticles against $S$. aureus was 1.5 , indicating that the nanoparticles prepared in the current study can be considered bactericidal agents. ${ }^{[12]}$

$50 \mu \mathrm{g} / \mathrm{mL}$ of silver nanoparticles was found to be effective against methicillin-resistant $S$. aureus when observed after streaking on Muller Hinton agar plates and incubated for 24 hours. Initially, after 5 minutes, the size of the streaks thinned out, and after 15 minutes, two or three colonies were grown on the streak, but after 30 minutes of incubation with silver nanoparticles, the plate showed complete lysis, and no bacterial colony was observed on the agar plates.

When tested together, the combination of antibiotics and nanoparticles worked effectively and showed a synergistic effect against methicillin-resistant $S$. aureus. Tetracycline and erythromycin were added in combination with silver nanoparticles separately. The enhancement of the antibacterial activity of silver nanoparticles with antibiotics was observed by measuring the zone of inhibition's diameter. Silver nanoparticles together with tetracycline inhibited methicillin-resistant $S$. aureus producing zone of inhibition of $30.3 \mathrm{~mm}$, whereas the silver nanoparticles together with erythromycin inhibited methicillin-resistant $S$. aureus producing zone of inhibition of $27 \mathrm{~mm}$. The positive synergistic interaction of mix ture with pathogen was due to bonding reaction.

\section{Cytoplasm Leakage Analysis}

Silver nanoparticle injured cells were often reported to release ninhydrin-positive materials, purine, and pyrimidine into a suspension. ${ }^{[18]}$ Nucleic acid was well known to absorb UV light at $260 \mathrm{~nm}$ range. The presence of silver nanoparticles in a suspension created damage to methicillin-resistant $S$. aureus cells at the membrane level. The amount of nucleic acid released was higher in the silver nanoparticles (0.3) than in the control (0.18).

The amount of protein released in a suspension of the treated cells was estimated by the Bradford assay. The quantity of protein leaked from the cells was higher when the time increased from 1-hour (0.2) to 3 hours (0.7). The result of the Bradford assay indicated that most of the silver nanoparticle treated bacterial cells released intracellular material into the cell suspension. ${ }^{[18]}$ Mohammed and his colleagues found that bacteria treated with silver nanoparticles would leak more protein. ${ }^{[7]}$

\section{Mortality Rate of Artemia Nauplii}

The silver nanoparticle aggregated such that the guts were filled with particles showed significant mortality within 24 hours of exposure. The results were found to be in such a way that in control, the mortality was about $8 \%$, which was negligible. In a minimum concentration of $25 \mu \mathrm{g}$, the mortality was $38 \%$, and as the concentration increased from 50 to $75 \mu \mathrm{g}$, the mortality was increased from 58 to $74 \%$. When it was further exposed to 48 hours, it induced high mortality. After 48 hours, the mortality rate was increased, and even in $25 \mu \mathrm{g}$ concentration, about $46 \%$ mortality was observed, and in concentrations 50 and $75 \mu \mathrm{g}$, the mortality increased to 78 and $90 \%$. However, these effects were most likely due to the lack of food uptake since the guts were completely filled with the aggregates of silver nanoparticles. ${ }^{[20]}$

The aggregations of silver nanoparticles inside the gut of Artemia nauplii were observed under the light microscope. Artemia generally exhibited non-selective filter-feeding behavior; it consumed all particles that were below 50 microns in size. The amount of aggregation not only depended on the amount of concentration but also 


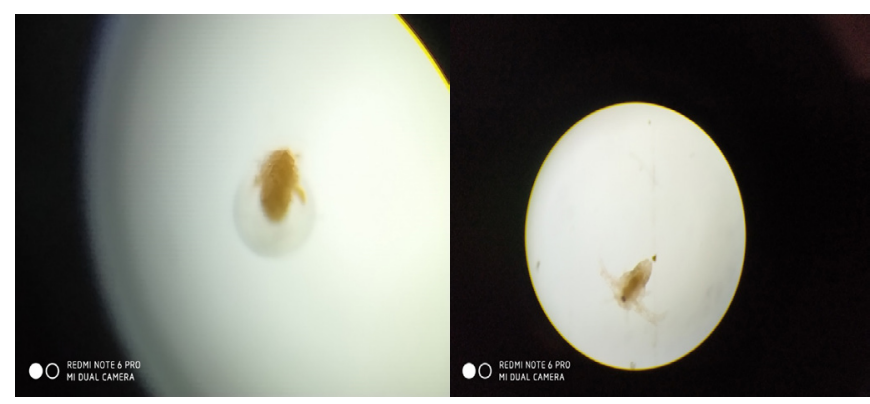

Fig. 9: Hatching of Artemia cysts treated with silver nanoparticles observed using light microscope (10 and 40X magnification)

depended on the amount of consumption of nanoparticles by each individual animal in various concentrations. ${ }^{[20]}$

\section{Hatching Percentage of Artemia Cyst}

This study revealed that the silver nanoparticles have an effect not only on the live animal but also on cysts. It is due to the diffusion of silver nanoparticles through the smooth outer layer of the cysts. The results were found after 24 hours to be in such a way that in control, the percentage of hatching was $84 \%$, which was normal. In a minimum concentration of $25 \mu \mathrm{g}$, the percentage of hatching was $70 \%$, and as the concentration increased from 50 and $75 \mu \mathrm{g}$, the percentage of hatching was about 64 and $42 \%$, correspondingly. Hence, the results revealed that as the concentration of the silver nanoparticles increased, the effect of toxicity increased, and the hatching percentage of Artemia cysts decreased (Fig. 9).

The silver nanoparticles had potential application in the field of biomedicine, and the procedure for synthesis is simple and had several advantages, such as, low cost, medical, and pharmaceutical application. In the future, it would be important to understand the biochemical and molecular mechanism of the synthesis of the silver nanoparticles by the cell filtrate.

\section{ACKNOWLEDGEMENT}

The authors thank Karunya University, Coimbatore, Kalasalingam Academy of Research and Education, Srivilliputhur and Yaazah Xenomics, Coimbatore, for performing SEM, XRD, and 16S rRNA sequencing.

\section{REFERENCES}

1. Nephawe MJ. Biosynthesis, characterization and antibacterial activity of silver and gold nanoparticles from the leaf and bark extracts of Zanthoxylum capense. Masters thesis. Univeristy of Johannesburg. 2015. http://ujcontent.uj.ac.za8080/10210/372050

2. Al-Thawadi S, Rasool AS, Youssef K. Antimicrobial activity of biosynthesized silver nanoparticles against $E$. coli and B. subtilis. J. Bioanal. Biomed. 2017;9:299-305.

3. Tripathi M, Kumar A, Kumar S. Characterization of silver nanoparticles synthesizing bacteria and its possible use in treatment of Multi drug resistant isolate. Front. Environ. Microbio. 2017;3(4):62-67.

4. Bergey's manual of determinative bacteriology ( 7 th ed.). Am J Public
Health Nations Health. 1964;54(3):544.

5. Yasmeen T, Essa A F, Faisal A, Urooj K S. Temporal expression of extracellular products of Staphylococcus aureus in vivo mouse cage model. J. Pak. Med. Assoc. 2012;539-545.

6. Kushwaha A, Singh VK, Bhartariya J, Singh P, Yasmeen K. Isolation and identification of $E$. coli bacteria for the synthesis of silver nanoparticles: Characterization of the particles and study of antibacterial activity. Eur. J. Exp. Biol. 2015;5(1):65-70.

7. Mohammed AE, Al-Qahtani A, al-Mutairi A, Al-Shamri B. Antibacterial and cytotoxic potential of biosynthesized silver nanoparticles by some plant extracts. Nanomaterials. 2018; 8(382):1-15.

8. Kumar MA, Jayeeta B, Sanjay K, Banerjee UC. Biosynthesis of silver nanoparticles: Elucidation of prospective mechanism and therapeutic potential. J. Colloid Interface Sci. 2014;415(1):39-47.

9. Mohanty S, Mishra S, Jena P, Jacob B, Sarkar B, Sonawane A. An investigation on the antibacterial, cytotoxic, and antibiofilm efficacy of starch-stabilized silver nanoparticles. NanomedNanotechnol. 2012;8(6):916-924.

10. Bauer AW, Kirby WMM, Sherris JC, Turck M. Antibiotic susceptibility testing by a standardized single disk method. Am. J. Clin. Pathol. 1966;45:493-496.

11. May J, Shannon K, King A, French G. Glycopeptide tolerance in Staphylococcus aureus. J. Antimicrob Chemother. 1998:42(2):189-197.

12. Woods, Washington. (1995). Principles and Practice of Infectious Diseases. 4 ed. Mandell, Bennett, and Dolin, Eds. New York: Churchill Livingstone.

13. Iroegbu CU, Okoli S. In vitro antibacterial activity of Synclisa scabrida whole root extracts. Afr. J. Biotechnol. 2005;4(9):946-952.

14. Sibanda T, Okoh A I. In vitro antibacterial regimes of crude aqueous and acetone ectracts of Garcinia kola seeds. J. Biol. Sci. 2008; (1):149-158.

15. Cwala Z, Igbinosa EO, Okoh AI. Assessment of antibiotics production potentials in four actinomycetes isolated from aquatic environments of the Eastern Cape Province of South Africa. African Journal of Pharmacy and Pharmacology. 2011;5(2):118-124.

16. Maruthai K, Vallayyachari K, Ravibalan T, Philip SA, Antony, Muthuraj M. Antibacterial activity of the silver nanoparticles against Escherichia coli and Enterobacter sp. Prog.Biosci. Bioeng. 2017;1(1):29-35.

17. Perveen S, Naqvi SB, Fatima A. Antimicrobial susceptibility pattern of clinical isolates from cases of ear infection using amoxicillin and cefepime. Springer plus. 2013;288(2):1-5.

18. Tiwari DK., Behari J, Sen P. Time and dose-dependent antimicrobial potential of Ag nanoparticles synthesized by top-down approach. Current science. 2008;95(5):647-655.

19. Manivasagan P, Gnanam S, Kannan S, Thangaradjou T, Vijayalakshmi S, Balasubramanian T. Antimicrobial and cy totoxic activities of an Actinobacteria (Streptomyces sp. PM-32) isolated from an offshore sediments of the Bay of Bengal in Tamil Nadu. Adv.Biol. Res. 2009; 3(5-6):231-236.

20. Arulvasu C, Jennifer S, Prabhu D, Chandhirasekar D. Toxicity effect of silver nanoparticles in Brine shrimp Artemia. Sci.World J. 2014;1-11.

21. Schmid, Riediker. Use of nanoparticles in swiss industry: a targeted survey. Environ. Sci.Technol. 2008;42(7):253-2260.

22. Perugini P, Simeoni S, ScaliaS et al. Effect of nanoparticle encapsulation on the photostability of the sunscreen agent, 2-ethylhexyl-pmethoxycinnamate. Int. J. Pharm. 2002;246(1-2):37-45.

23. Kumar A, Kumar S, Kumar P, Arumugam P. Synthesis and characterization of silver nanoparticles using E. coli. BioMedRx. 2013;4(1):382-385.

24. Koilparambil D, Kurian L, Vijayan S, Shaikmoideen JM. Green synthesis of silver nanoparticles by Escherichia coli: analysis of antibacterial activity. J. Water and Environ Nanotechnol. 2016; 1(1):63-74.

25. Kumar N, Das S, Jyoti A, Kaushik S. Synergistic effect of silver nanoparticles with Doxycycline against Klebsiella pneumoniae. Int. J. Pharm. Pharm Sci. 2016;8(7):183-186.

HOW TO CITE THIS ARTICLE: Sharon SFB, Ganesan A. Biosynthesis, characterization, bactericidal, and toxic effect of silver nanoparticles using Klebsiella pneumoniae strain STC1. Int. J. Pharm. Sci. Drug Res. 2020;12(5):525-531. DOI: 10.25004/IJPSDR.2020.120514 